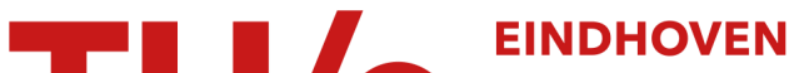 \\ UNIVERSITY OF \\ TECHNOLOGY
}

\section{On the early-age behavior of zero-slump concrete}

Citation for published version (APA):

Husken, G., \& Brouwers, H. J. H. (2012). On the early-age behavior of zero-slump concrete. Cement and Concrete Research, 42(3), 501-510. https://doi.org/10.1016/j.cemconres.2011.11.007

DOI:

10.1016/j.cemconres.2011.11.007

Document status and date:

Published: 01/01/2012

Document Version:

Accepted manuscript including changes made at the peer-review stage

Please check the document version of this publication:

- A submitted manuscript is the version of the article upon submission and before peer-review. There can be important differences between the submitted version and the official published version of record. People interested in the research are advised to contact the author for the final version of the publication, or visit the $\mathrm{DOI}$ to the publisher's website.

- The final author version and the galley proof are versions of the publication after peer review.

- The final published version features the final layout of the paper including the volume, issue and page numbers.

Link to publication

\section{General rights}

Copyright and moral rights for the publications made accessible in the public portal are retained by the authors and/or other copyright owners and it is a condition of accessing publications that users recognise and abide by the legal requirements associated with these rights.

- Users may download and print one copy of any publication from the public portal for the purpose of private study or research.

- You may not further distribute the material or use it for any profit-making activity or commercial gain

- You may freely distribute the URL identifying the publication in the public portal.

If the publication is distributed under the terms of Article $25 \mathrm{fa}$ of the Dutch Copyright Act, indicated by the "Taverne" license above, please follow below link for the End User Agreement:

www.tue.nl/taverne

Take down policy

If you believe that this document breaches copyright please contact us at:

openaccess@tue.nl

providing details and we will investigate your claim. 


\title{
On the early-age behavior of zero-slump concrete
}

\author{
G. Hüsken *, H.J.H. Brouwers \\ Eindhoven University of Technology; Department of the Built Environment, P.O. Box 513, 5600 MB Eindhoven, The Netherlands
}

\section{A R T I C L E I N F O}

Article history:

Received 31 May 2011

Accepted 11 November 2011

\section{Keywords:}

Zero-slump concrete (A)

Green-strength $(\mathrm{C})$

Compaction behavior (A)

Intensive compaction test $(C)$

\begin{abstract}
A B S T R A C T
This paper presents experimental investigations and analyses on the early-age-behavior of zero-slump concrete, such as compaction behavior and green-strength. First, the influence of the granulometric properties of the fines is discussed in detail. For this purpose, the early-age behavior of two different fines (quartz flour and fly ash) is investigated by means of the intensive compaction test (IC-test). The tests on the influence of the fines focus on effects caused by differences in the particle shape and the use of a plasticizing admixture. The conducted tests on the compaction behavior of the fines and their corresponding green-strength are extended to continuously graded granular mixes. Here, the influence of optimized particle packing on the early-age behavior is presented and a comparison on the basis of the aforementioned quartz flour and fly ash is made. In this consideration, experimental investigations on the early-age behavior of a zero-slump concrete mix and possible effects on the hardened concrete properties are included.
\end{abstract}

(c) 2011 Elsevier Ltd. All rights reserved.

\section{Introduction}

Zero-slump concrete, also known as no-slump concrete or earthmoist concrete, is used for the production of concrete mass products, such as sewage pipes, concrete slabs, paving blocks, masonry blocks, roofing tiles, and curbstones. The early-age behavior of this type of concrete is characterized by its low water content and stiff consistency, which is corresponding to a slump of $6 \mathrm{~mm}$ or less [11]. Therefore, in contrast to normal strength, normal weight concrete with plastic consistency, the characteristics of zero-slump concrete allow for direct stripping of the unhardened product after filling and vibrating the mold and subsequent transport to a place with defined curing conditions [19]. This phenomenon of the fresh concrete is referred to as green-strength and allows for short processing times and enables an efficient use of molds and production machines. The term green-strength is defined by [1] as strength of the unhardened product to keep its original shape until the cement starts to set and the hydration products provide sufficient strength. Despite the greenstrength of the unhardened concrete, the filling and compaction behavior of the fresh concrete mix characterize the early-age behavior of that type of stiff concrete.

As outlined before, the early-age behavior of zero-slump concrete is important for the production of concrete mass products and is governed by a number of different parameters. In this case, both compaction behavior and green-strength of the fresh concrete are influenced by the granulometric properties of the fines, the content of fines in the mix, the water content of the mix, and the surface tension of

\footnotetext{
* Corresponding author.

E-mail address: g.husken@tue.nl (G. Hüsken).
}

the wetting liquid. By means of the present study, the IC-tester will be used to investigate the influence of the aforementioned parameters on the compaction behavior and the green-strength and conclusions to the apparent cohesion and internal friction of zero-slump concrete will be made. This investigation includes also the possible effect of a denser granular structure on the compressive strength and scaling resistance of the hardened concrete.

\section{Early-age behavior of zero-slump concrete}

The green-strength of the fresh concrete can be explained by means of soil mechanical models that are also used for the description of cohesive soils $[1,17]$. However, it has to be mentioned at this point that the cohesive character of zero-slump concrete is differing from the real cohesion that can be found in cohesive soils like clay. According to [2], this real cohesion is only obtained by soils that adhere after wetting and subsequent drying and where significant forces are required for breaking up the hardened structure of the dry material. Although this mechanism cannot be adapted to zero-slump concrete completely, the Mohr-Coulomb failure criterion, as depicted in Fig. 1, allows for the explanation of the green-strength of zeroslump concrete. In this context, the green-strength of zero-slump concrete is governed by the apparent cohesion that is expressed by the real cohesion (intersection point of the tangent in Fig. 1) of cohesive soils and the internal friction of the material that is represented by the inclination of the tangent in Fig. 1. The cohesive character of zero-slump concrete in its fresh state and the resulting greenstrength is caused by the formation of capillary forces. It has to be mentioned at this point that both effects, formation of interparticle forces and internal friction of a granular mix, are depending on the grain size and shape of the involved particles. 


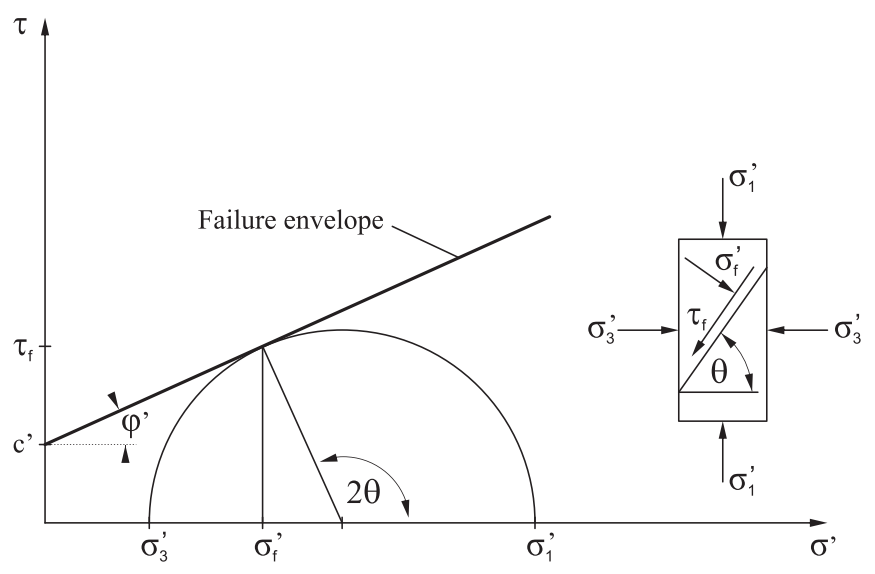

Fig. 1. Stress conditions of the Mohr-Coulomb failure criterion [2].

Capillary forces are formed at the contact points of the fine particles as a result of the partly saturated void fraction of the granular skeleton. This partial saturation of the void fraction causes the formation of liquid bridges between the smaller particles at their contact points (cp. Fig. 2). An attractive force is formed in the liquid bridge that is depending on the diameter $D$ of the involved particles (here assumed to be an ideal particle with spherical shape), the surface tension $\gamma$ of the wetting liquid, the resulting contact angle between the surface of the liquid and the particle surface, and the distance between the involved particles. The formation of liquid bridges between the fine particles is a rather complex system and the calculation of the resulting capillary forces is only possible for ideal particles having a spherical shape [18]. Hence, a dimensionless parameter of the normalized adhesive force $F_{a d h}$ between two ideal particles is given by [15], which allows for an estimation of the adhesive force as follows:

$F_{a d h} \approx \pi \cdot \gamma \cdot D$.

Even though the exact calculation of the adhesive force $F_{a d h}$ between irregular particles in real granular systems results in rather complex equations that are causing problems in their solution, basic phenomena can be explained by the existing theoretical models, which help to understand the interaction of the fine particles and their influence on the early-age behavior of zero-slump concrete.

One of these important mechanisms is the formation of capillary forces $F_{\text {cap }}$ in the liquid bridges between two particles in real granular systems and the expansion of the liquid bridges until the void fraction

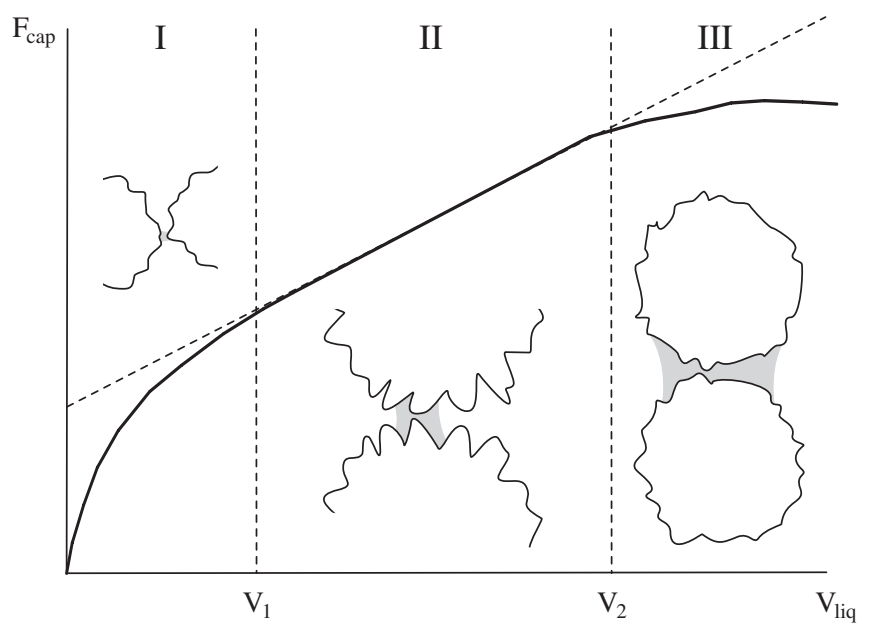

Fig. 2. Behavior of the wetting liquid between two rough spherical particles: I asperity regime, II roughness regime, III spherical regime [4]. of the granular skeleton is completely filled by the wetting liquid. The formation of liquid bridges can be described according to [4] by three regimes as a function of the added liquid volume $V_{\text {liq }}$. The three regimes are illustrated schematically in Fig. 2 and their influence on the resulting capillary force $F_{\text {cap }}$ in real granular systems is also depicted. The three regimes are as follows:

Asperity regime at low water content smaller than $V_{1}$, where liquid bridges are formed by the accumulation of liquid around the asperities at which two adjacent particles are in contact. According to [4], this process continues until the lateral extension of the liquid filled region exceeds the lateral dimension of the asperity. At that state, the capillary force is only influenced by the formation of liquid bridges around asperities at the contact points of two particles.

Roughness regime for liquid volumes larger than $V_{1}$, where the liquid bridge expands laterally around the asperity in a region that is still small enough that the macroscopic curvature of the particle shows no influence on the liquid bridge. However, the volume of the liquid bridge exceeds the volume around a single asperity as the liquid bridge expands laterally. During this regime, the increase of the capillary force is proportional to the volume of the added liquid.

Spherical regime for liquid volumes larger than $V_{2}$, where the liquid bridge is influenced by the macroscopic curvature of the particle as the volume of the liquid in the contact area exceeds the lateral dimension of one or more asperities. A further increase of the liquid volume results now in an increase of the capillary force that reaches a constant value.

\section{Experimental program}

The early-age behavior of zero-slump concrete gives this type of stiff concrete a special feature that allows for direct stripping of the concrete products and short process times as the unhardened product can be transported to a place with defined curing conditions. However, the handling of the unhardened product requires a minimum strength of the fresh concrete so that the product keeps its original shape during transportation and storage without undesired deformations. In the case of concrete sewage pipes, insufficient strength of the unhardened product can even result in a total collapse of the product during transportation in the early-age. To minimize the number of deficient products, insights on the green-strength and related influencing factors, such as granulometric properties of the mix, influence of chemical admixtures, and water content are required. Therefore, the influence of the fines on the early-age behavior and the green-strength was investigated in the first instance and provided the basis for the further investigations on continuously graded granular mixes.

\subsection{Materials}

As outlined before, the compaction behavior and the greenstrength of zero-slump concrete are governed by the granulometric properties as well as the water demand of the fines. Hence, two different fines have been selected in order to investigate their influence on the early-age behavior. The selected fines are a quartz flour and a fly ash with a similar particle size distribution (PSD). The PSDs of the selected fines are depicted in Fig. 3. The quartz flour was chosen, as it is an inert fine material that does not react with water, but having similar granulometric properties as cement (PSD and angular particle shape). That way, the influence of the proceeding hydration on the early-age behavior is prevented. The selected fly ash is characterized by a similar PSD as determined for the quartz flour, but having particles with a more spherical shape. Furthermore, the selected fly ash is considered to be inert when mixed with water. Besides the influence 


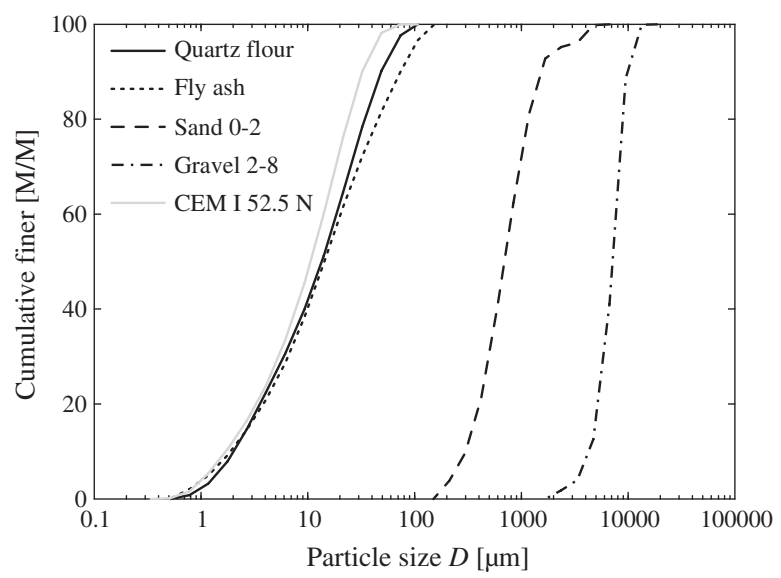

Fig. 3. PSDs of the selected materials used for the experimental investigations.

of the granulometric properties of the fines, the effects of chemical admixtures on the early-age behavior were investigated. A polycarboxylate-based superplasticizer (SP1) was selected for that purpose and applied in combination with the selected fines. Fig. 4 illustrates the influence of the selected SP on the surface tension of the wetting liquid. The measurements of the surface tension have been performed on a Krüss K11 tensiometer using the plate method.

For the design of continuously graded granular mixes, a river sand $0-2$ and a river gravel 2-8 were selected. Both aggregate fractions consist primarily of quartz and were dredged from areas along the Lower Rhine. The PSD of the sand $0-2$ and the gravel 2-8 is depicted in Fig. 3. The experimental investigations on continuously graded mixes were extended to full-scale tests on concrete for which an ordinary Portland cement (CEM I $52.5 \mathrm{~N}$ ) was selected.

\subsection{Mix designs}

The experimental investigations that were carried out in the first instance on the selected fines (quartz flour and fly ash) were extended to continuously graded mixes having a maximum particle size of $8 \mathrm{~mm}$. The continuously graded mixes were designed using the optimization algorithm introduced by [7]. This optimization algorithm uses the modified Andreasen and Andersen equation suggested by [3] and which follows from:

$P(D)=\frac{D^{q}-D_{\min }^{q}}{D_{\max }^{q}-D_{\min }^{q}}$

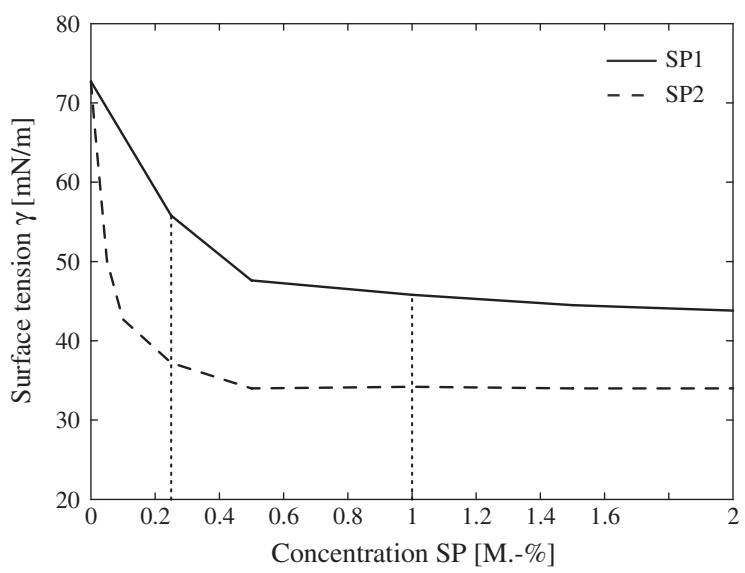

Fig. 4. Influence of two different superplasticizers on the surface tension of water and applied concentrations of $S P 1$. The measurements have been performed on a Krüss K11 tensiometer using the plate method. with $P(D)$ as cumulative finer volume fraction of the particle size $D$, $D_{\max }$ and $D_{\min }$ giving the maximum and minimum particle size of the mix, respectively, and $q$ determining the distribution modulus of the grading curve. By means of this algorithm, continuously graded granular mixes, which are composed of varying raw materials, can be designed that follow a given grading curve, expressed by Eq. (2), with lowest deviation.

Two different distribution moduli of $q=0.25$ and $q=0.40$ were used to compose granular mixes with a high $(q=0.25)$ and low ( $q=0.40$ ) content of fines, respectively. The selected quartz flour as well as the fly ash was used as fines in the designed granular mixes $(Q 1, Q 2, F 1, F 2)$ in order to ensure comparable conditions and to relate the fundamental properties of the fines to the results obtained on continuously graded granular mixes. The mixes were designed in that way that comparable conditions regarding the content of fines for equal distribution moduli $q$ were achieved. The mix designs that are presented in Table 1 are based on a water content $\Psi_{m}$ of about 3.0 M.-\% till 3.25 M.-\%. The corresponding PSDs of the designed mixes are depicted in Fig. 5.

Based on the insights obtained from the experimental investigations carried out on the selected quartz flour and fly ash as well as continuously graded granular mixes thereof, two zero-slump concrete mixes have been designed (Opti1, Opti2) and compared with a mix design (Original) that is used for the production of concrete paving blocks by an industrial partner. For testing these mixes, the same aggregates as discussed before were applied and an ordinary Portland cement (CEM I $52.5 \mathrm{~N}$ ) was used as binder in combination with the selected fly ash. Further details on the designed mixes are listed in Table 1 and the corresponding PSDs are depicted in Fig. 6.

\subsection{Intensive compaction test}

The selected fines as well as the designed mixes were mixed with water and tested for their compaction behavior to study the influence of varying water content. The compaction behavior was tested using the IC-test as this test provides an accurate and convenient method to evaluate the workability of granular mixes with respect to their compaction behavior. Consequently, the IC-test was also used by other researchers, such as [9] as well as [10].

The method and the equipment of the IC-test were developed by I. Paakkinen in 1984 in Finland [14] and were later adopted by the Nordtest method [12]. The sample is compacted by a combination of pressure and shear movement without the use of vibration energy. This principle is referred to as shear-compaction principle (cp. Fig. 7). The pressure is introduced to the sample by compressing it

Table 1

Mix proportioning and mix characteristics of the designed mixes used for the experimental investigations.

\begin{tabular}{|c|c|c|c|c|c|c|c|}
\hline & \multicolumn{7}{|c|}{ Mix composition $\left[\mathrm{kg} / \mathrm{m}^{3}\right]$} \\
\hline & Q1 & Q2 & $F 1$ & $F 2$ & Original & Opti1 & Opti2 \\
\hline \multicolumn{8}{|l|}{ Material } \\
\hline Quartz flour & 520.5 & 290.4 & - & - & - & - & - \\
\hline Fly ash & - & - & 477.6 & 237.2 & 114.0 & 215.5 & 150.0 \\
\hline CEM I $52.5 \mathrm{~N}$ & - & - & - & - & 261.6 & 250.0 & 250.0 \\
\hline Sand 0-2 & 995.3 & 909.5 & 949.5 & 933.7 & 1536.5 & 1033.6 & 1154.8 \\
\hline Gravel 2-8 & 844.3 & 1160.6 & 846.5 & 1164.3 & 373.0 & 723.2 & 715.8 \\
\hline Water & 79.4 & 79.2 & 76.3 & 71.0 & 112.5 & 128.0 & 114.7 \\
\hline \multicolumn{8}{|c|}{ Mix characteristics } \\
\hline $\begin{array}{l}\text { Distribution modulus } \\
\quad q\end{array}$ & 0.25 & 0.40 & 0.25 & 0.40 & - & 0.30 & 0.30 \\
\hline$w / p$ ratio & 0.15 & 0.27 & 0.16 & 0.30 & 0.29 & 0.27 & 0.28 \\
\hline$w / c$ ratio & - & - & - & - & 0.43 & 0.51 & 0.46 \\
\hline$\Psi_{m}($ M.-\%) & 3.25 & 3.25 & 3.25 & 3.0 & 4.7 & 5.4 & 4.8 \\
\hline Fines $\left[\mathrm{kg} / \mathrm{m}^{3}\right]$ & 520.5 & 290.4 & 477.6 & 237.2 & 387.3 & 474.0 & 409.6 \\
\hline Paste $\left[\mathrm{l} / \mathrm{m}^{3}\right]$ & 275.8 & 188.8 & 292.3 & 178.3 & 253.8 & 310.2 & 267.7 \\
\hline
\end{tabular}




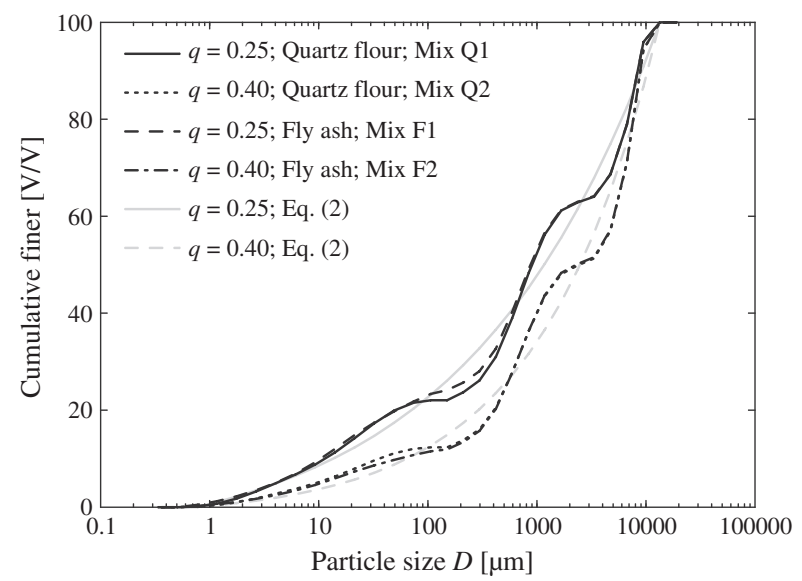

Fig. 5. PSD of the designed granular mixes used for the experimental investigations on the early-age behavior; $D_{\max }=11.2 \mathrm{~mm}, D_{\min }=0.63 \mu \mathrm{m}$.

between the top and bottom plate of the sample cylinder, whereas the gyratory movement of the sample cylinder is resulting in shear forces. The gyratory movement of the sample is caused by the slightly inclined ends of the sample, which are rotating around the central axis of the sample cylinder during the test [8]. A complete rotation of the sample around the fixed axis is defined as one working cycle. The applied pressure, rotation speed, as well as the inclination of the sample to the vertical axis of the device can be adjusted and kept constant during each test. During the test, the IC-tester measures the height of the sample and the shear force and calculates the resulting density based on the sample's mass given to the program. All values can be recorded for later data analysis. Fig. 7b depicts the data that were obtained by the IC-test for two different mixes of zero-slump concrete.

As mentioned before, the parameters of the IC-test, such as applied pressure, rotation speed, as well as the inclination of the sample to the vertical axis, can be adjusted. In order to obtain constant test condition, the following parameters have been used to produce samples with a diameter of $100 \mathrm{~mm}$ and a height of about $100 \mathrm{~mm}$ :

- Cylinder inclination $\left(\alpha_{I C T}\right): 40 \mathrm{mrad}$

- Compaction pressure: $250 \mathrm{kPa}$

- Working speed: $60 \mathrm{rpm}$

- Duration $(N)$ : 100 cycles.

Possible variations in the height of the sample caused by improved compaction behavior and higher packing fractions were compensated

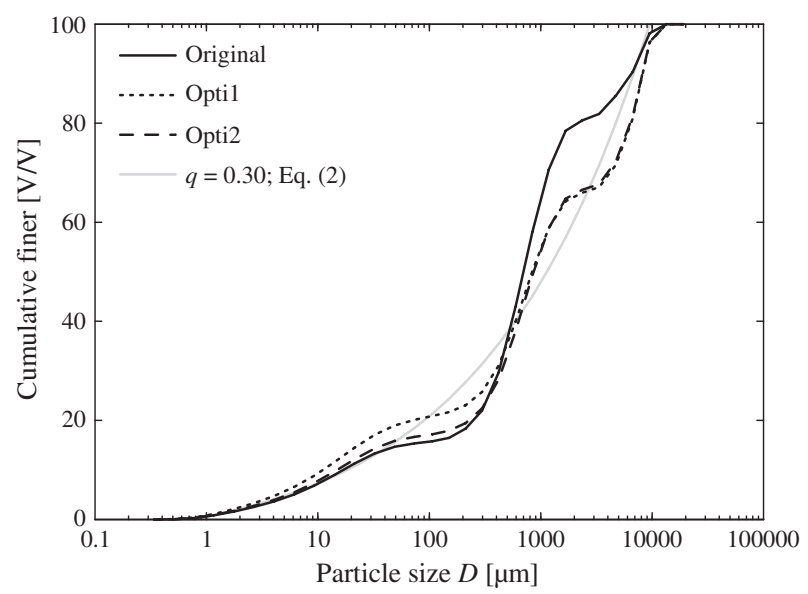

Fig. 6. PSD of the commercial mix and mixes with optimized grading using the new mix design concept; $D_{\max }=11.2 \mathrm{~mm}, D_{\min }=0.96 \mu \mathrm{m}$. by an increased sample mass so that a constant height of about $100 \mathrm{~mm}$ was obtained for all samples.

\subsection{Green-strength}

The samples that have been produced by the IC-tester were stripped from the sample holder directly after the test was finished and subsequently tested for their green-strength in the fresh state. Stress-strain relations using a uniaxial compressive strength test were used to evaluate the green-strength in this research. Therefore, the fresh samples have been subjected to compressive stresses. The uniaxial compressive strength test was performed on a Zwick Z020 testing machine. All samples were tested displacement-controlled with a crosshead speed of $1 \mathrm{~mm} / \mathrm{min}$ until the sample failed and the resulting force and axial deformation were recorded.

\subsection{Hardened concrete tests}

For the hardened concrete tests, cylindrical samples having a diameter of $100 \mathrm{~mm}$ were produced from the mixes denominated as Original, Opti1 and Opti2 (cp. Table 1). The samples were compacted using the IC-tester and subsequently cured after compaction in a humid cabinet at $95 \%$ relative humidity and $21{ }^{\circ} \mathrm{C}$ for one day. After hardening in the humid cabinet, the samples were submerged in water until their test age was reached.

The produced samples were tested for their compressive strength after 28 days and 91 days, respectively. For this purpose, the produced samples were ground before they were submitted to compressive strength to obtain a constant height of $100 \mathrm{~mm}$, resulting in a diameter to height ratio of unity, and to ensure that the surfaces for introducing the load are parallel. Besides the compressive strength test, samples were tested for their deicer-scaling resistance according to SS 137244 (slab test). This test was performed on disks that were cut from the produced cylindrical samples. The dimensions of the cut disks amount to $100 \mathrm{~mm}$ in diameter and $50 \mathrm{~mm}$ in height. The preparation of the samples was done according to the requirements described in SS 137244 and the samples were submitted to 56 freeze-thaw cycles at the age of 31 days. The applied temperature profile of one freeze-thaw cycle is depicted in Fig. 8.

\section{Results and discussion}

\subsection{Compaction behavior}

\subsubsection{Fines}

The influence of the selected fines on the compaction behavior was investigated using the IC-test with the corresponding parameters as mentioned in Section 3.3 and the obtained results are depicted in Fig. 9 for pastes made with quartz flour and fly-ash and varying water content.

It is evident from the data illustrated in Fig. 9 that both fines differ in their compaction behavior to a large extent. The fly ash results in higher packing fractions for comparable water contents than the quartz flour and less water is required to obtain the so-called 'slurry point' that is characterized by a complete saturation of the void fraction. This fact can be related to the difference in the particle shape of the applied fines. The selected fly ash is mainly composed of spherical particles compared to the more angular particles of the quartz flour. [6] reports a shape factor $\xi$ of 1.09 for the applied fly ash, whereas a value of about 1.4 has to be considered for the quartz flour. The shape factor $\xi$ expresses the ratio of the effective surface area of a particle to the surface area of an ideal sphere with equal volume [6]. According to this definition, a lower value of $\xi$ corresponds to a more spherical particle shape, which results in a value of 1.0 for spheres. 
a

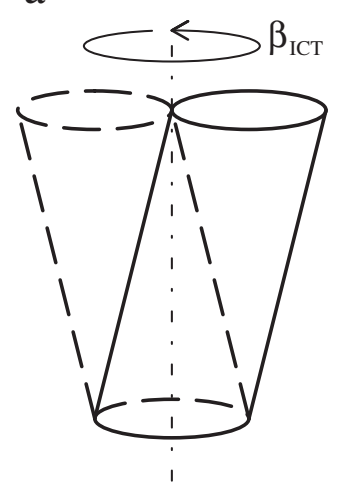

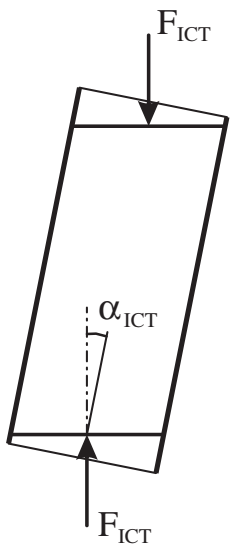

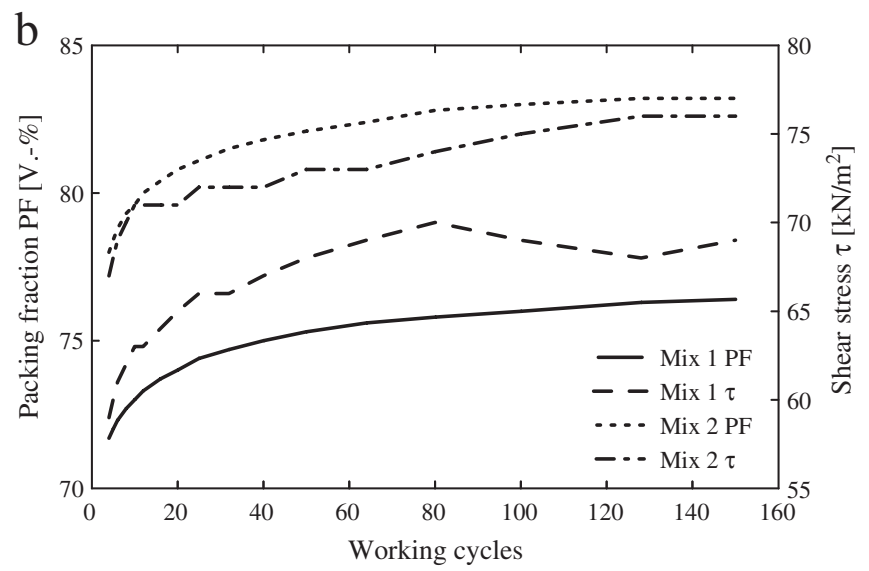

Fig. 7. a) Schematic illustration of the working principle of the IC-test [10]. b) Packing fraction PF and shear rate $\tau$ versus compaction cycles for two different mixes.

The more spherical shape of the fly ash particles and the resulting ball-bearing effect show a beneficial influence on the compaction behavior and the final packing fractions that were obtained (cp. Fig. 9). In contrast to this, the angular shape of the quartz flour increases the internal friction of the mix and lower values of the packing fraction were obtained for comparable compaction efforts and water content.

\subsubsection{Chemical admixtures}

Besides the effect of the granulometric properties of the fines, the influence of chemical admixtures on the early-age behavior was investigated. For this purpose, the compaction behavior and the green-strength of the fines were determined for a fixed water content, but varying SP concentration (SP1). The water content was fixed to be $12.9 \mathrm{M}$.-\% for the quartz flour and $8.2 \mathrm{M}$.-\% for the fly ash. The investigated SP concentration of the mixing water amounts to 0.25 M.-\% and 1.0 M.-\%, respectively (cp. Fig. 4). The compaction behavior of the samples was investigated by means of the IC-test in two different ways. In the first instance, the sample was compacted to the same packing fraction as obtained by the tests without SP and the required working cycles as well as the green-strength were determined. Next, the sample was compacted using the same compaction efforts as applied for the tests without SP (100 working cycles) and the influence on the compaction behavior and the greenstrength was determined. The shaded values depicted in Fig. 9 show the packing fractions that were obtained for different SP concentrations (SP1). Detailed values of the conducted tests are given in Table 2.

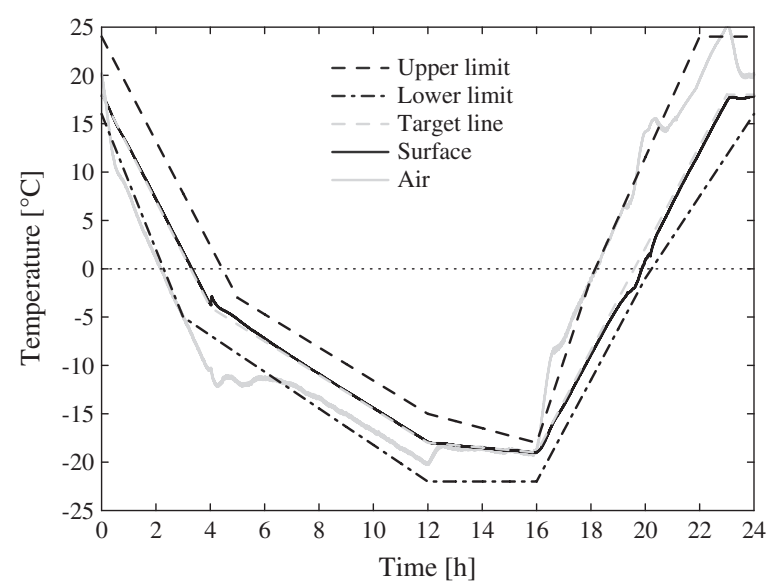

Fig. 8. Applied temperature profile of one freeze-thaw cycle and measured temperature of the sample's surface and within the cooling chamber.
The test results demonstrate that the compaction behavior is improved when a plasticizing admixture is used and that this effect is depending on the SP concentration. In both cases, quartz flour and fly ash, less working cycles were required to obtain equal packing fractions as determined for the tests without SP. The same holds for the packing fractions that were obtained for equal compaction efforts. Here, the packing fractions after 100 working cycles increased with increasing SP content.

\subsubsection{Grading}

The experimental investigations on the influence of the fines on the compaction behavior were extended to continuously graded mixes. For that purpose, the four different mixes with varying distribution moduli $q$ as listed in Table 1 were used. The results of the ICtest are depicted in Fig. 10.

The assumption of the beneficial effect of spherical particles on the compaction behavior is also confirmed for continuously graded granular mixes (see Figs. 10a and b). This fact was already demonstrated by the experimental investigations carried out on the fines only and applies for both investigated distribution moduli of $q=0.25$ and $q=0.40$. Furthermore, the experimental data reveal that a lower distribution modulus $q$ results in better compaction behavior and higher packing fraction. This effect is more evident for the applied fly ash than for the quartz flour. Here, the higher content of spherical particles increased the packing fraction of the fly ash mixes to a remarkable extent. The maximum packing fraction of the tested fly ash mixes increased from $85.8 \%$ to $87.9 \%$ when a distribution modulus

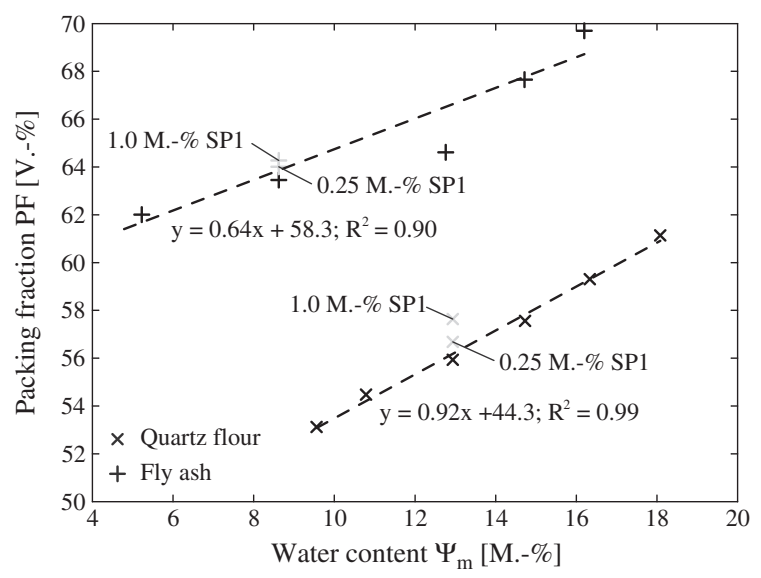

Fig. 9. Packing fractions of pastes made with quartz flour and fly-ash for varying water contents $\Psi_{m}$ (mass-based). The shaded values represent comparable measurements with a SP content of 0.25 M.-\% and 1.0 M.-\%, respectively. 

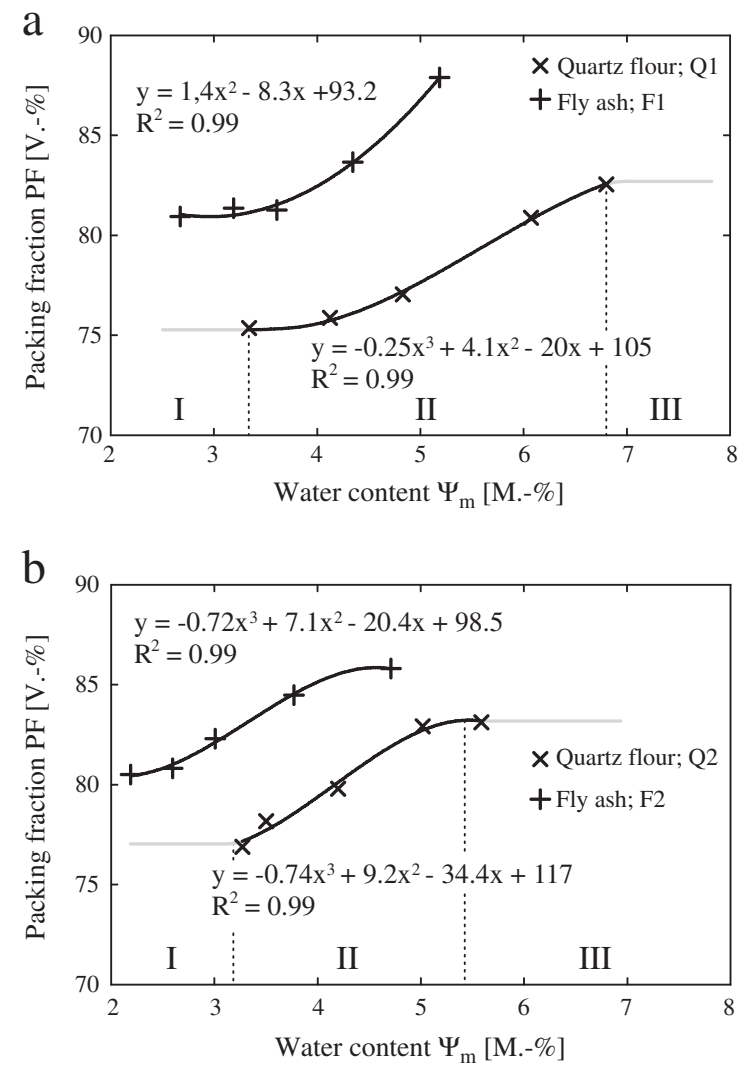

Fig. 10. Packing fraction of the tested mixes for varying water content $\Psi_{m}$ (massbased) and suggested compaction regimes (I - dry state, II - moist state, III - wet state): a) $q=0.25$; and b) $q=0.40$.

of $q=0.25$ was used instead of $q=0.40$. Furthermore, an insight into the sensitivity of the designed mixes on changes in their water content is provided by the data depicted in Fig. 10a and $\mathrm{b}$ and will be discussed in the following using the designed quartz flour mixes as example.

As illustrated in Fig. 10a, the graph obtained by the IC-test for varying water content of the quartz flour mix Q1 differs from the compaction curve of the classical Proctor test as explained by [1,2]. The Proctor test gives a value for the optimum water content at which highest dry density of the sample is obtained. This point of optimum water content for highest packing fraction was not obtained by the IC-test. Here, the compaction behavior can be divided into three regimes as illustrated in Fig. 10a and which are:

Dry state that is represented by the shaded horizontal line in sector I of Fig. 10a. In this state, variations in the water content of the mix show no or only minor effects on the packing fraction. The water content of the mix is too low to form water layers around the particles that have a lubricating effect and that

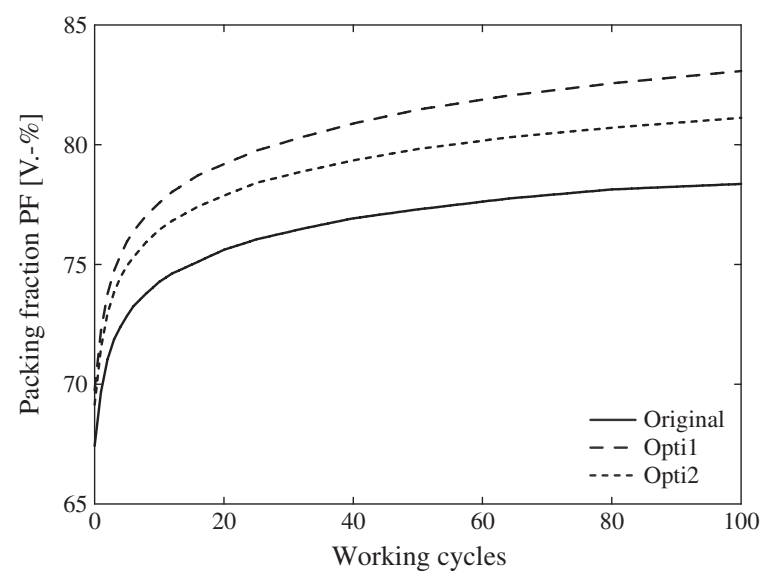

Fig. 11. Graphs obtained by the IC-test showing the influence of the grading on the compaction behavior of the optimized mixes.

improve the compaction behavior. Therefore, the packing fraction in this state is equal to the dry conditions or only slightly higher. Moist state that is illustrated by the black solid line in sector II of Fig. 10a. The lubricating effect of the particles grows in this state and the packing fraction increases with increasing water content. This state determines the optimum range for the practical application of zero-slump concrete in production.

Wet state that is indicated by the shaded horizontal line in sector III of Fig. 10a and that is determined by the so-called 'slurry point' of the sample. In this state, a further increase in the water content is not resulting in higher packing fraction as the granular mix obtained the highest possible densification and minimum void fraction. A further increase in the water content shows no positive effect on the packing fraction and excessive water drains only from the compacted sample as the remaining void fraction is saturated with water. At this point, the degree of saturation $S_{w}$ of the void fraction is larger than $90 \%$.

The range of the moist state determines the aforementioned sensitivity of the designed mix on changes in its water content. The width of sector II is depending on the content of fines and increases with decreasing distribution modulus $q$ (cp. Figs. 10a and b). Consequently, mixes with a lower distribution modulus $q$ are less sensitive to small changes in their water content due to their higher amount of fines and their compaction behavior is less affected.

Analyzing the data that are depicted in Fig. 11, the positive effect of improved particle packing and the beneficial influence of the fines on the compaction behavior are again demonstrated. In this case, the grading of a concrete mix used for the production of concrete paving blocks was optimized considering the aforementioned aspects. The final packing fraction of the original mix increased from about $78.6 \%$ to $81.2 \%$ (Opti2) and $83.4 \%$ (Opti1), respectively. Both higher fines and gravel content characterize the optimized mixes with higher packing fraction. As stated in the Introduction, it is expected that a higher content of coarse aggregates results in higher

Table 2

Test results of the IC-test for different SP concentrations and compaction regimes.

\begin{tabular}{|c|c|c|c|c|c|c|}
\hline & \multicolumn{3}{|c|}{ Quartz flour } & \multicolumn{3}{|l|}{ Fly ash } \\
\hline & No SP & $0.25 \%$ SP1 & $1.0 \% \mathrm{SP} 1$ & No SP & $0.25 \%$ SP1 & $1.0 \% \mathrm{SP} 1$ \\
\hline Working cycles ${ }^{\#}$ & 100 & 71 & 41 & 100 & 83 & 62 \\
\hline Packing fraction ${ }^{\dagger}[$ V.-\%] & 55.9 & 56.7 & 57.6 & 63.5 & 64.0 & 64.3 \\
\hline Green-strength $^{\#} \sigma_{\text {gre }}\left[\mathrm{N} / \mathrm{mm}^{2}\right]$ & 0.127 & 0.102 & 0.095 & 0.080 & 0.062 & 0.066 \\
\hline Green-strength $^{\dagger} \sigma_{\text {gre }}\left[\mathrm{N} / \mathrm{mm}^{2}\right]$ & 0.127 & 0.119 & 0.125 & 0.080 & 0.076 & 0.075 \\
\hline
\end{tabular}

\#Determined for equal packing fraction as obtained without SP addition.

${ }^{\dagger}$ Determined after 100 working cycles. 
internal stresses and, consequently, lower packing fractions for similar compaction efforts. However, this was not observed in the considered case as here the higher content of fly ash showed a beneficial effect on the compaction behavior due to the ball-bearing effect. This contribution of the fly ash becomes also evident when the fly ash content is considered. Here, the mix with the highest fly ash content (Opti1) obtained also the highest packing fraction of about $83.4 \%$.

\subsection{Green-strength}

\subsubsection{Fines}

Information on the deformation behavior and the green-strength of the selected fines can be derived from the stress-strain graphs depicted in Figs. 12a and b. Although the more spherical shape of the fly ash particles and the resulting ball-bearing effect influenced the compaction behavior and the final packing fractions in a positive way, the green-strength of the tested fly ash samples was influenced negatively. Here, higher green-strength was measured for the quartz flour samples than for the fly ash ones. This fact demonstrates that the internal friction of the mix has a larger influence on the greenstrength than the packing fraction or the water content of the mix. The maximum green-strength that was obtained near the slurry point amounts to $0.173 \mathrm{~N} / \mathrm{mm}^{2}$ for the quartz flour having a water content of 18.2 M.-\%. The corresponding value of the tested fly ash amounts to $0.161 \mathrm{~N} / \mathrm{mm}^{2}$ for a water content of $16.2 \mathrm{M}$.-\%.

Moreover, information on the deformation behavior of the tested samples can be derived from the graphs depicted in Fig. 12a and b. The higher internal friction of the quartz flour samples results not only in higher green-strength, but has also an effect on the deformation behavior near the maximum load. In this range, larger plastic deformations were measured for the quartz flour than for the tested fly ash. The fly ash samples showed a rapid decrease in their green-
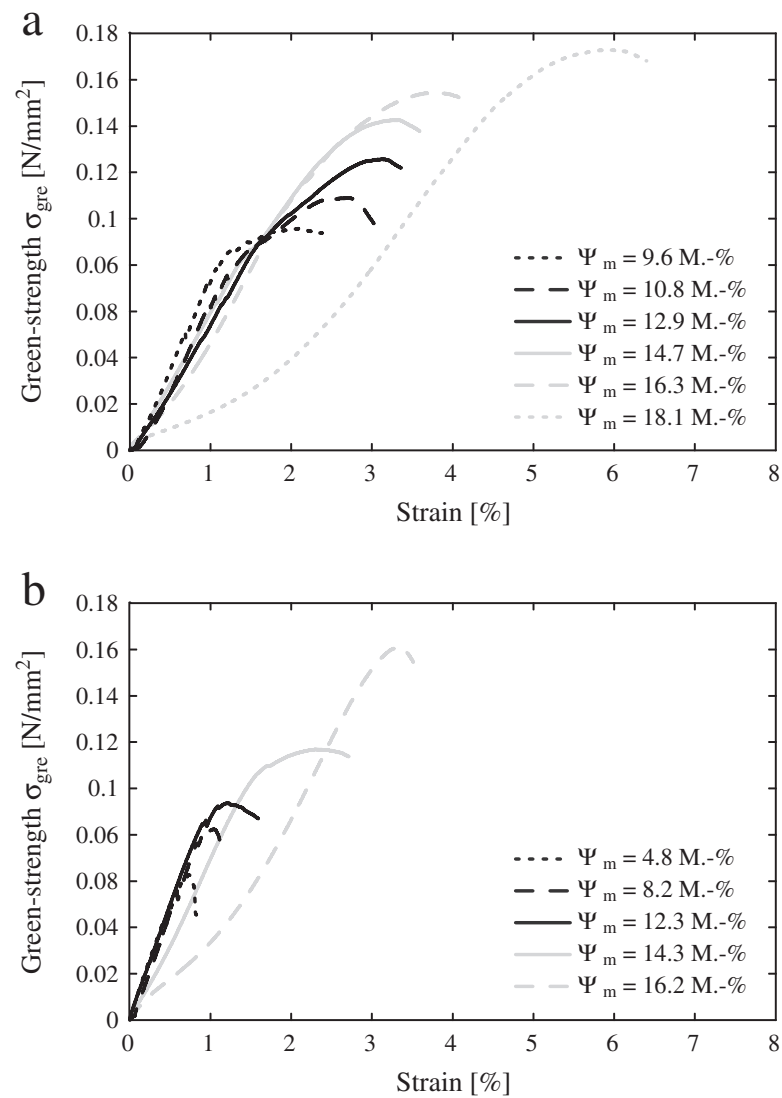

Fig. 12. Stress-strain curves of the tested fines for varying water contents $\Psi_{m}$ (massbased): a) quartz flour; and b) fly ash. strength when the maximum load was reached and which was not observed for the quartz flour. Larger plastic deformations in the range of the maximum load were measured for the tested fly ash samples only for higher water contents. This confirms that the grain interlocking is an important aspect for the green-strength of fresh concrete and the deformation resistance of the concrete in its earlyage.

A further interesting fact was observed for the deformation behavior of the samples near the so-called slurry point. At this point, the remaining void fraction of the samples is almost saturated with water and the degree of saturation amounts to values larger than $90 \%$. According to the definitions given by [15] as well as [4], the capillary forces should decrease at this point as liquid bridges are not existing anymore or reach at least a constant value (cp. Fig. 2). Consequently, the green-strength of the samples should also decrease near the slurry point. However, this was not the case as highest greenstrength was measured at this point and indicates, again, that the internal friction, as a result of particle shape and high packing fraction, dominates the green-strength.

\subsubsection{Chemical admixtures}

It was demonstrated by the measurements using the IC-tester that the applied SP improved the compaction behavior of the tested fines. The application of a plasticizing admixture is not only influencing the compaction behavior, but shows also an effect on the green-strength as illustrated in Figs. 13a and b.

The green-strength of the tested samples that were compacted to the same packing fractions as obtained without SP addition decreased with increasing SP content. This fact demonstrates that the greenstrength is also affected by the surface tension of the wetting liquid and that with increasing SP content the surface tension decreases. Considering Eq. (1), a lower surface tension $\gamma$ results in lower
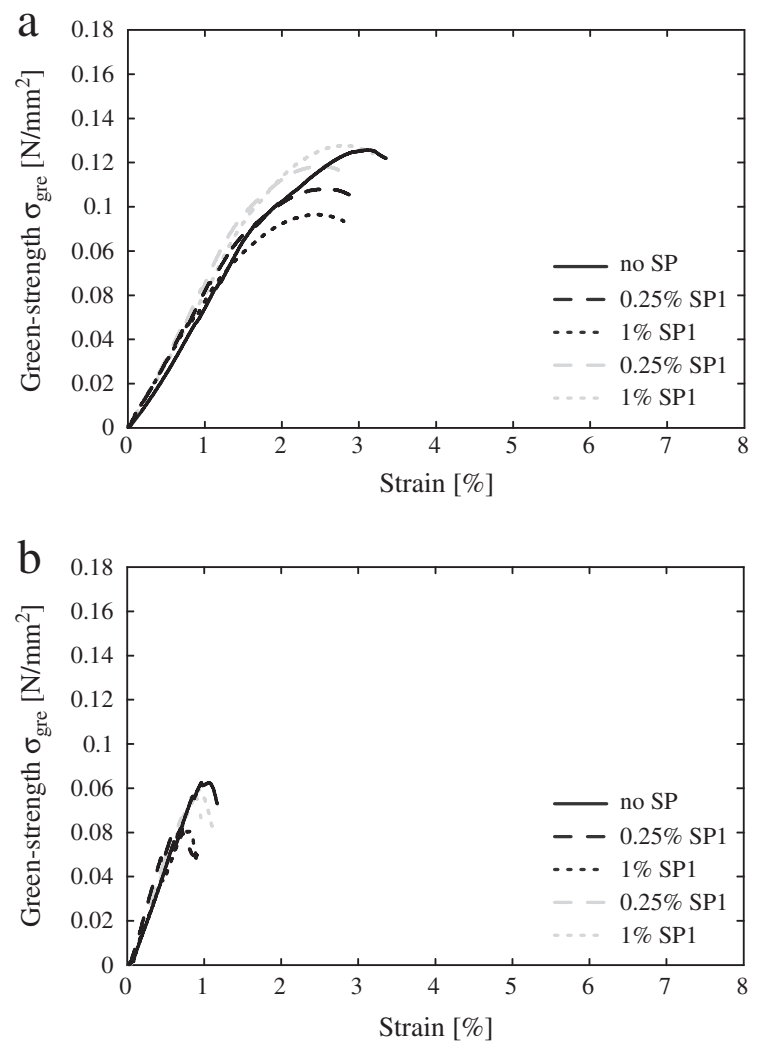

Fig. 13. Stress-strain curves for constant water content $\Psi_{m}$ (mass-based) and varying SP content: a) quartz flour, $\Psi_{m}=12.9$ M.-\%; and b) fly ash, $\Psi_{m}=8.2$ M.- $\%$. The shaded graphs show the stress-strain curves that were obtained after 100 working cycles with similar SP content. 

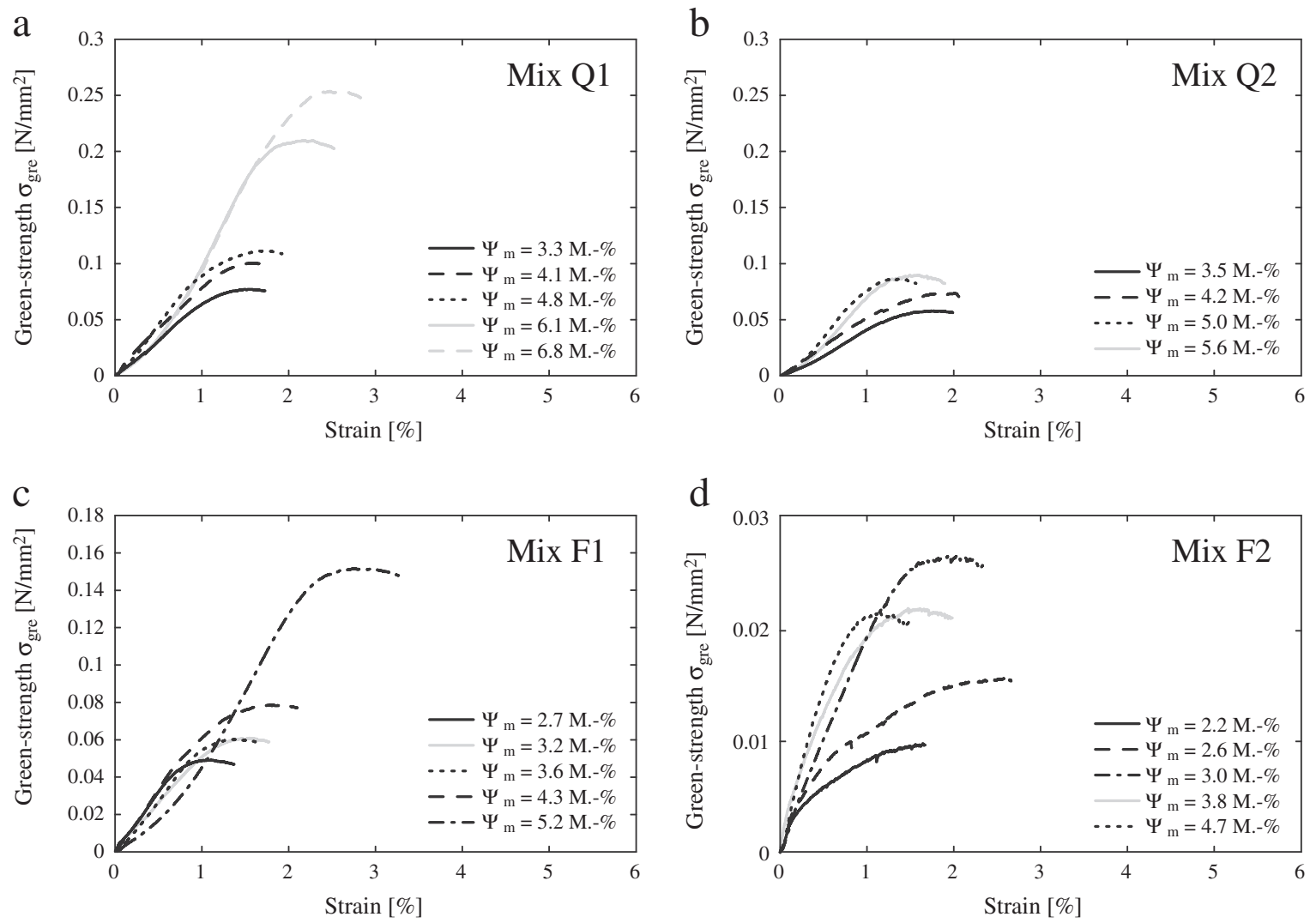

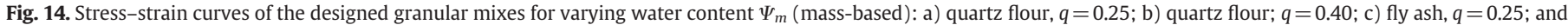
d) fly ash, $q=0.40$.

adhesive forces between the fine particles and decreases therefore the green-strength (cp. Fig. 4, Fig. 13a as well as b).

This negative effect, caused by the lower surface tension of the wetting liquid, is compensated when equal compaction efforts are applied. In this case, the packing fraction after 100 working cycles increases and similar values of the green-strength are obtained as illustrated by the shaded graphs in Figs. 13a and b.

\subsubsection{Grading}

Variations on the granulometric properties of the designed mixes, such as fines content and particle shape of the fines, have not only an impact on the compaction behavior, but influence also the greenstrength of the fresh mix. As illustrated by the data depicted in Figs. 14a and b, the green-strength of the mixes containing quartz flour was decreasing with increasing distribution modulus $q$ and decreasing fines content. Similar observations are reported by [1], which are explained by the higher cohesive character of mixes with a high paste content. Furthermore, the higher fines content improves the compaction behavior of the mix and more contact points of particles in the micro range exist. Similar observations were made for the mixes containing fly ash, which are depicted in Figs. 14c and d.

Although the spherical shape of the fly ash improved the compaction behavior and was resulting in higher packing fractions (cp. Figs. 10a and b), the green-strength of these samples is lower than that of samples containing quartz flour. This fact is related to the lower internal friction of the mixes containing fly ash. In this respect, the packing fraction of mixes that contain more spherical fines was higher than for similar mixes with angular fines and is mainly caused by the ball-bearing effect and the lower grain interlocking of the spherical fines, which also resulted in lower green-strength values.

The beneficial effect of the fly ash on the compaction behavior and the resulting higher packing fractions improved the green-strength of the optimized concrete mixes (Opti1, Opti2). Both mixes show higher green-strength than the original mix design. The use of angular fines (cement) and spherical fines (fly ash) resulted in an ideal combination that achieves higher packing due to the ball-bearing effect of the fly ash, but also higher green-strength caused by the angular cement particles and the higher internal friction that is connected with the higher packing fractions. The latter fact is demonstrated in Fig. 15 by the higher green-strength values that were obtained for higher packing fraction.

Besides the positive effect of improved particle packing on the compaction behavior and the green-strength, another interesting fact becomes evident from the data depicted in Fig. 15. The numbering of the particular graphs corresponds to the sequence in which the samples have been produced by the IC-test. The time that was required for compacting the sample using the IC-test and the subsequent compressive strength test was about $8 \mathrm{~min}$ so that the last

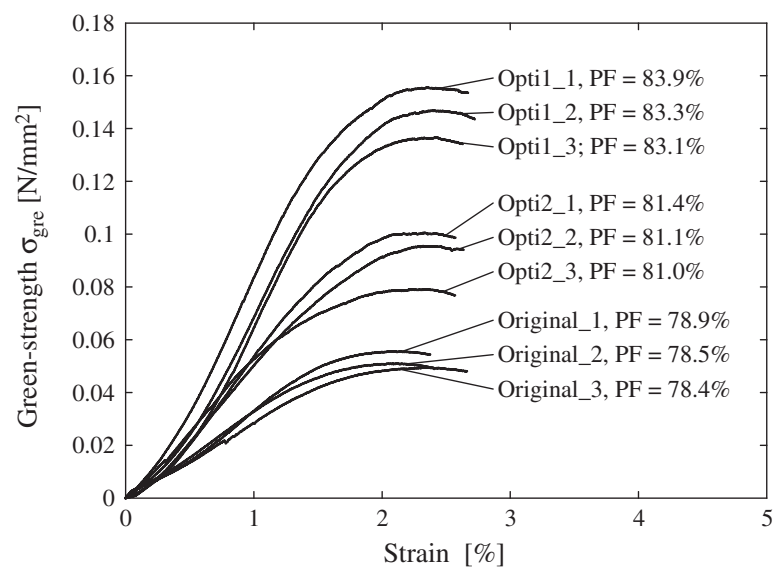

Fig. 15. Stress-strain curves of the original concrete mix and the optimized mixes. 
Table 3

Hardened concrete properties of the samples and corresponding packing fractions obtained by the IC-test, and deicing scaling results classified according to [16].

\begin{tabular}{|c|c|c|c|}
\hline & Original & Opti1 & Opti2 \\
\hline Packing fraction [V.-\%] & 78.6 & 83.4 & 81.2 \\
\hline Calculated air content [V.-\%] & 10.2 & 3.8 & 7.3 \\
\hline 28 days compr. strength $\left[\mathrm{N} / \mathrm{mm}^{2}\right]$ & 17.0 & 33.5 & 23.1 \\
\hline 91 days compr. strength $\left[\mathrm{N} / \mathrm{mm}^{2}\right]$ & 21.6 & 43.5 & 32.9 \\
\hline \multicolumn{4}{|l|}{ Deicer-scaling resistance } \\
\hline Scaling after 14 cycles $\left[\mathrm{g} / \mathrm{m}^{2}\right]$ & 42.5 & 144.3 & 101.9 \\
\hline Scaling after 28 cycles $\left[\mathrm{g} / \mathrm{m}^{2}\right]$ & 107.3 & 266.1 & 186.0 \\
\hline Scaling after 56 cycles $\left[\mathrm{g} / \mathrm{m}^{2}\right]$ & 157.9 & 408.4 & 272.5 \\
\hline $\mathrm{M}_{56} / \mathrm{M}_{28}$ & 1.5 & 1.5 & 1.5 \\
\hline Assessment & Good & Good & Good \\
\hline
\end{tabular}

sample was compacted about 16 min after mixing. During that time, the mixing bowl was covered with a plastic to avoid evaporation of water from the sample. However, with progressing time, a decrease in the final packing fraction and the obtained green-strength becomes obvious, a fact that was also observed by other measurements on concrete mixes using the IC-test. Due to the experimental conditions, the evaporation of water from the sample is considered to be negligible. A possible explanation for the lower packing fractions over time can therefore only be given by the high reactivity of the applied cement (CEM I $52.5 \mathrm{~N}$ ). It is assumed that the proceeding hydration of the cement has an influence on the compaction behavior of the samples, which was possible to measure by the high accuracy of the IC-test. The lower packing fractions that were obtained over time resulted also in less internal friction and lower green-strength as depicted in Fig. 15.

\subsection{Compressive strength}

The results of the compressive strength test are listed in Table 3. The data confirm that improved particle packing results in higher packing fractions of the solids and in improved mechanical properties due to a denser granular structure. Similar results were also reported by [7] for zero-slump concrete mixes with optimized particle packing. In this case, the compressive strength of the original mix amounts to $17.0 \mathrm{~N} / \mathrm{mm}^{2}$ after 28 days and was increased by optimizing the grading of the solids to a value of $33.5 \mathrm{~N} / \mathrm{mm}^{2}$ (Opti1). Even though the cement content of mix Opti2 is the same, the compressive strength after 28 days is lower and amounts to $23.1 \mathrm{~N} / \mathrm{mm}^{2}$. The lower compressive strength of mix Opti2 is mainly caused by the lower packing fraction that was obtained. Here, the higher fly ash content of mix Opti1 showed a beneficial effect both on the compaction behavior and the hardened concrete properties.

\subsection{Deicer-scaling resistance}

The results of the test on the deicer-scaling resistance and their assessment according to the criteria given by [16] are listed in Table 3. In general, all samples can be classified as concrete with good deicer-scaling resistance. However, a large difference in the results was noted and the concrete with the lowest compressive strength obtained also the lowest scaling after 56 freeze-thaw cycles. This difference is caused by a number of influencing factors that have a large influence on the durability of concrete due to their interrelation. In this respect, the following factors can be addressed.

The original mix that shows the lowest scaling has also the lowest $\mathrm{w} / \mathrm{c}$ ratio and the scaling increases with increasing $w / c$ ratio. This is in line with findings reported by e.g. [16]. Considering the $w / c$ ratio, higher $w / c$ ratio reduces the freeze-thaw resistance of concrete as more capillary pores are formed that govern the permeability of the cement paste and the transport of water in the concrete.
A further factor that influences the freeze-thaw resistance of concrete is the content of air pores. This is an important factor for the freeze-thaw resistance of zero-slump concrete and is also discussed by [5]. A higher content of accessible pores increases the freezethaw resistance of concrete as the freezing water can expand into the void fraction of theses pores. In this context, the connection between the pores is also important. The data listed in Table 3 indicate that the lowest scaling was obtained by the sample with the highest calculated air content. This leads to the conclusion that with increasing packing fraction the content of accessible air pores decreases and the connectivity of the existing pores is influenced in a negative way.

Despite the negative influence of the aforementioned two mechanisms, all tested samples fulfill the requirements on the deicingscaling resistance as prescribed in DIN-EN 1338:2003 and can be characterized as concrete with good freeze-thaw resistance.

\subsection{Discussion}

Factors that influence the early-age behavior of zero-slump concrete were investigated and have been discussed in this paper. The experimental results reveal that the compaction behavior and the greenstrength of zero-slump concrete are affected to a large extent by the granulometric properties and the shape of the fines. In view of the compaction behavior, spherical particles increase the packing fraction of zero-slump concrete mixes, but reduce their green-strength as the internal friction of the mix is reduced due to less grain interlocking. In this respect, angular particles, such as the applied quartz flour, show a beneficial effect on the green-strength, but lower packing fractions are obtained. Furthermore, it was demonstrated that the internal friction of the granular mix has a larger impact on the green-strength of zero-slump concrete than the formation of capillary forces that are formed in the liquid bridges between the fines. The internal friction of the mix depends on the particle shape of the fines and the obtained packing fraction, which is depending on the water content of the mix. However, higher green-strength was obtained for mixes of angular particles although their packing fraction was lower than that of mixes with spherical particles.

The application of a plasticizing admixture improved the compaction behavior, but reduced also the green-strength for similar packing fractions. This negative effect of plasticizing admixtures on the greenstrength is related to their influence on the surface tension. As illustrated in Fig. 4, the surface tension of the wetting liquid decreases with increasing content of a plasticizing admixture and results in lower adhesive forces between the fine particles. This decrease in the green-strength was compensated when the sample was compacted by means of the same compaction effort as applied to a mix without the use of a plasticizing admixture. In this case, the application of the plasticizing admixture increased the final packing fraction, which was resulting in higher internal friction of the sample and comparable green-strength as obtained for samples without a plasticizing admixture.

The compaction behavior and the green-strength of continuously graded mixes following the modified Andreasen and Andersen equation (Eq. (2)) is improved when low distribution moduli $q$ are applied. Lower values of $q$ result in mixes with a higher fines content that improves the compaction behavior of the mix as the friction between the coarser aggregates is reduced and, consequently, higher packing fractions are obtained that result in higher internal friction and improved green-strength. In this respect, spherical particles increased the packing fraction of the mix to a larger extent than angular particles, but reduced the green-strength due to less grain interlocking between the fines.

Based on the findings on the influence of the granulometric properties of the fines on the early-age behavior of zero-slump concrete, the results of improved particle packing on the fresh and hardened concrete properties of a commercial zero-slump concrete mix are shown. Tests using the IC-test were carried out to investigate the 
compaction behavior and further influences on the green-strength and the hardened concrete properties.

In this context, the optimized mixes (Opti1, Opti2) resulted in higher packing fractions than the original mix design. This fact is related to the higher paste content of these mixes and the ball-bearing effect of the applied fly ash. The increased packing fraction of the optimized mixes led to a remarkable increase of the compressive strength of the hardened concrete and a more efficient cement use. Despite the beneficial effect of a denser granular structure on the mechanical properties of the produced samples, the durability of the produced samples in respect to their freeze-thaw resistance was not improved. Although all samples fulfill the requirements on the freeze-thaw resistance as prescribed in DIN-EN 1338:2003, samples with higher packing fraction were also more susceptible for deicer-scaling.

\section{Conclusions}

Based on the experimental investigations on the early-age behavior of zero-slump concrete and the obtained results, the following conclusions can be drawn:

- The early-age behavior of zero-slump concrete is mainly influenced by the granulometric properties of the fines. In this respect, the particle shape has a large impact on both compaction behavior and green-strength.

- It was demonstrated that spherical particles achieve higher packing fractions than angular particles that have the same PSD. In contrast to this, higher green-strength was achieved with mixes of angular particles although their packing fractions were lower than obtained for comparable tests using spherical particles.

- The green-strength of zero-slump concrete is a result of internal friction and adhesive forces, which are generated in the liquid bridges that are formed between the fines. It was demonstrated that the internal friction has a larger impact on the green-strength than the formation of liquid bridges. Furthermore, the particle shape and the packing fraction of the mix govern the internal friction of zeroslump concrete mixes, whereas the particle shape has a larger influence than the packing fraction. Considering a constant particle shape, higher packing fractions increase the internal friction of the mix.

- Higher packing fractions were obtained when the entire grading of the mix was optimized using the modified Andreasen and Andersen equation (Eq. (2)). In this respect, lower values of the distribution modulus $q$ resulted in mixes with a higher fines content and a better compaction behavior. Consequently, the void fraction of the granular structure was reduced to a further extent and the greenstrength was increased substantially.

- The application of a plasticizing admixture improved the compaction behavior and resulted in higher packing fractions for comparable compaction efforts. However, the green-strength was reduced for comparable packing fractions as obtained for mixes without addition of a plasticizing admixture. However, this negative effect on the green-strength was compensated by the higher packing fractions that were obtained when the mix was compacted using the same compaction efforts as applied for mixes without addition of a plasticizing admixture.

- The influence of improved particle packing on both fresh and hardened concrete properties of a zero-slump concrete mix was demonstrated. In this respect, the compaction behavior of a zeroslump concrete mix was improved by optimized grading of the solids. The packing of the aggregates was improved and the denser granular structure resulted in higher green-strength of the fresh concrete and higher compressive strength of the hardened concrete.

- Even though the early-age behavior of the optimized zero-slump concrete mix was improved and higher compressive strength was achieved, the freeze-thaw resistance of the optimized mixes was lower than that of the reference mix.

\section{Acknowledgments}

The authors wish to express their thanks to the following sponsors of the research group: Bouwdienst Rijkswaterstaat, Graniet-Import Benelux, Kijlstra Betonmortel, Struyk Verwo, Insulinde, Enci, Provincie Overijssel, Rijkswaterstaat Directie Zeeland, A\&G Maasvlakte, BTE, Alvon Bouwsystemen, v.d. Bosch Beton, Selor, Twee "R" Recyling, GMB, Schenk Concrete Consultancy, De Mobiele Fabriek, Creative Match, Intron, Geochem Research, Icopal and BN International (chronological order of joining).

\section{References}

[1] Bornemann, R. (2005). Untersuchung zur Modellierung des Frisch- und Festbetonverhaltens erdfeuchter Betone, Ph.D. thesis, University of Kassel, Kassel, Germany (in German).

[2] R.F. Craig, Soil Mechanics, 6th edn Spoon Press, London, UK, 1994.

[3] J.E. Funk, D.R. Dinger, Predictive Process Control of Crowded Particulate Suspensions: Applied to Ceramic Manufacturing, Kluwer Academic Press, Boston, US 1994.

[4] T.C. Halsey, A.J. Levine, How sandcastles fall, Phys. Rev. Lett. 80 (14) (1998) 3141-3144.

[5] C. Häring, Freeze-thaw resistance for earth-moist concrete's, BFT Int.: Concrete Plant + Precast Technol. 66 (4) (2000) 96-102.

[6] Hunger, M. (2010). An integral design concept for ecological self-compacting concrete, PhD thesis, Eindhoven University of Technology, Eindhoven, The Netherlands.

[7] G. Hüsken, H.J.H. Brouwers, A newmix design concept for earth-moist concrete: a theoretical and experimental study, Cem. Concr. Res. 38 (10) (2008) 1246-1259 Erratum, ibid 39 (9) 832.

[8] Invelop, Intensive Compaction Tester: Operating Instructions, Invelop Oy, Savonlinna, Finland, 2005.

[9] K.J. Juvas, Very dry precasting concretes, in: P.J.M. Bartos, D.L. Marrs, D.J. Cleland (Eds.), Production Methods and Workability of Concrete, E \& FN Spon, London, UK, 1996, pp. 153-168.

[10] A. Käppi, E. Nordenswan, Workability of no-slump concrete, Concr. Int. 29 (3) (2007) 37-41.

[11] S.H. Kosmatka, B. Kerkhoff, W.C. Panarese, N.F. MacLeod, R.J. McGrath, Design and Control of Concrete Mixtures, 7th Canadian Edn, Cement Association of Canada, Ottawa, Canada, 2002.

[12] NT BUILD 427, Compactibility with IC-tester, Nordtest Method, Nordtest, Espoo, Finland, 1994.

[13] I. Paakkinen, Intensive compaction tester device for testing the compactability of no-slump concrete, Nordic Concrete Research Publication, 1986, pp. 109-116, No. 5.

[14] H. Rumpf, Mechanische Verfahrenstechnik, Carl Hanser Verlag, München, Germany, 1975 (in German).

[15] J. Stark, B. Wicht, Dauerhaftigkeit von Beton: Der Baustoff als Werkstoff, Birkhäuser, Basel, Switzerland, 2001 (in German).

[16] M. Schmidt, Erdfeuchte Betone - Anforderungen, Verarbeitbarkeit, Grünstandfestigkeitund Prüfverfahren, BFT Int.: Concrete Plant + Precast Technol. 65 (11) (1999) 14-24.

[17] H. Schubert, Kapillarität in porösen Feststoffsystemen, Springer Verlag, Berlin, Germany, 1982 (in German).

[18] Stutech, Aardvochtig Beton, Stutech report No. 22, STUTECH - Studievereniging Betontechnologie, Den Bosch, The Netherlands, 2005 (in Dutch). 